JJTM, Vol. 5 No. 3, November 2017

\title{
PENGARUH MODEL PEMBELAJARAN KOOPERATIF TIPE EXAMPLE NON EXAMPLE TERHADAP HASIL BELAJAR CHASIS SISWA KELAS XI TKR II DI SMK NEGERI 3 SINGARAJA TAHUN PELAJARAN 2017/2018
}

\author{
Oleh
I Gusti Ngurah Wirya Kusuma Putra ${ }^{1}$, I N. Pasek Nugraha ${ }^{2}$, K. Rihendra Dantes ${ }^{3}$
1,2,3 Jurusan Pendidikan Teknik Mesin, Fakultas Teknik dan Kejuruan
Universitas Pendidikan Ganesha \\ E-mail.wiryakusuma329@gmail.com ${ }^{1}$, paseknugraha@undiksha.ac.id ${ }^{2}$,
rihendra79@gmail.com ${ }^{3}$
}

\begin{abstract}
Abstrak
Penelitian ini dilakukan untuk mengetahui adanya pengaruh model pembelejaran kooperatif tipe Example Non Example terhadap hasil belajar chasis siswa kelas XI TKR II di SMK Negeri 3 Singaraja. Metode penelitian yang digunakan dalam penelitian ini yaitu dengan desain One-shoot Case Study. Pemilihan sampel pada penelitian ini menggunakan teknik sampel acak. Sampel pada penelitian ini sebanyak 34 orang kelas XI TKR II sebagai kelas eksperimen. Setelah pemberian perlakuan berupa penerapan model pembelajaran kooperatif tipe Example Non Example, siswa diberikan tes berupa tes objektif yang sebelumnya sudah dilakukan uji validas isi, validitas butir, tingkat kesukaran, daya beda dan reliabilitas. Setelah didapatkan data, kemudian dilakukan analisis menggunakan uji-t satu pihak. Hasil penelitian menunjukan bahwa terdapat pengaruh model pembelajaran kooperatif tipe Example Non Example terhadap hasil belajar chasis siswa kelas XI TKR II di SMK Negeri 3 Singaraja. Hal ini ditunjukan dengan hasil uji-t dengan $\mathrm{t}$-hitung $=37,96, \mathrm{dk}=\mathrm{n}-1=34$, dan taraf signifikan $5 \%$ didapat $\mathrm{t}$ tabel=2,0345. Dengan demikian t-hitung lebih besar dari pada t-tabel, maka $\mathrm{H}_{0}$ ditolak dan $\mathrm{H}_{1}$ diterima dan berarti terdapat pengaruh yang signifikan model pembelajaran kooperatif tipe Example Non Example terhadap hasil belajar chasis siswa kelas XI TKR II di SMK Negeri 3 Singaraja.
\end{abstract}

Kata Kunci: Model Pembelajaran Kooperatif TipeExample Non Example, Hasil Belajar, One-shoot Case study.

\begin{abstract}
This research was conducted to find out the influence cooperative learning model Example Non Example type of class student chasis learning XI TKR II in SMK Negeri 3 Singaraja. The method is used in this this research by design One-shoot Case Study. The sample selection in this study used class random sampling technique. The samples in this study were 34 students of class XI TKR II as experimental class. After implementing cooperative learning model Example Non Example, students are given objective test that have previously been tested for observation, objective test, validity item, level of difficulty, different capacity and reliability. After obtaining the data then analayzed using t-test. The result of the research shows that there is influence cooperative learning model Example Non Example type of class student chasis learning XI TKR II in SMK Negeri 3 Singaraja. This is indicated by the t-test and t-count $=37.96, \mathrm{dk}=\mathrm{n}-1=34$, and $5 \%$ significant level obtained t table $=2.0345$. thus $\mathrm{t}$-count is greater than t-table, then $\mathrm{H}_{0}$ is rejected and $\mathrm{H}_{1}$ accepted and it means there is a significant influence cooperative learning model
\end{abstract}


JJTM, Vol. 5 No. 3, November 2017

Example Non Example type of class student chasis learning grade XI TKR II in SMK Negeri 3 Singaraja.

Keywords: Cooperative Learning Model Example Non Example, Learning Outcomes, One-shoot Case Study.

\section{PENDAHULUAN}

Pendidikan yang bermutu merupakan hal yang sangat penting dalam kemajuan suatu bangsa. Hal ini menuntut pemerintah untuk menciptakan sumber daya manusia yang berkualitas tinggi dan memiliki kemampuan dalam memanfaatkan sumber daya yang ada. Untuk menciptakan sumber daya manusia yang berkualitas tinggi harus dilalui dengan proses belajar. Peranan guru dalam dunia pendidikan sangatlah penting yaitu memiliki kemampuan dalam hal mendidik, mengajar, melatih siswa dengan baik. Selain itu, seorang guru juga dituntut harus mampu memberikan teladan bagi siswanya agar kelak menjadi manusia yang unggul dan berguna. Proses pembelajaran dapat menggunakan berbagai teori belajar maupun praktek langsung. Sesuai dengan diterapkannya Kurikulum 2013 bukan hanya guru saja yang dituntut untuk lebih inovatif dalam memilih metode yang akan digunakan untuk mengajar, namun siswa yang harus lebih aktif dalam proses pembelajaran agar proses pembelajaran siswa menjadi aktif dan termotivasi untuk belajar. Salah satu contoh diterapkannya Kurikulum 2013 adalah di Sekolah Menengah Kejuruan (SMK). Sekloah Menengah Kejuruan merupakan pendidikan kejuruan tingkat menengah atas yang diselenggarakan dalam rangka menyimpan tenaga kerja siap pakai dengan menjadi tenaga profesional yang memiliki keterampilan yang memadai, produktif, kreatif dan mampu berwirausaha. Salah satu contoh SMK yang menerapkan Kurikulum 2013 adalah SMK Negeri 3 Singaraja. Berdasarkan hasil wawancara pada tanggal 7 Februari 2017 yang dilakukan oleh peneliti di SMK N 3 Singaraja dengan guru kelas XI TKR II bahwa hasil belajar mata pelajaran Chasis sebagian besar siswa masih di bawah dari Kriteria Ketuntasan Minimal (KKM) yaitu 70,00. Hasil observasi lapangan tersebut disebabkan karena kecenderungan guru masih menggunakan media pembelajaran dengan metode ceramah yang kurang optimal dan penugasan dalam proses pembelajaran Chasis.

\section{Model Pembelajaran}

Model dapat diartikan sebagai suatu objek atau konsep yang digunakan untuk mempresentasikan suatu hal. Sesuatu yang nyata dan dikonversi untuk sebuah bentuk yang lebih komprehensif. Hakikat mengajar adalah membantu peserta didik memperoleh informasi, ide, keterampilan, nilai-nilai, cara berfikir, serta mengajak peserta didik agar menyadari dan secara sadar menggunakan strategi-strategi mereka sendiri untuk belajar. Menurut Raka Rasana (2009:1) "Model pembelajaran merupakan sebuah model atau sebuah prosedur yang sistematis dalam mengorganisasikan pengalaman belajar untuk mencapai tujuan pembelajaran". Model pembelajaran dapat dipandang sebagai titik awal dalam melaksanakan pembelajaran dan guru selanjutnya dapat menciptakan model pembelajaran sendiri, karena model pembelajaran hendaknya tidak dipandang sebagai resep, melainkan sebagai perangsang dalam melakukan pembelajaran.

Pembelajaran hendaknya dipandang sebagai upaya dalam menciftakan kondisi belajar yang mencakup materi, keterampilan, hubungan social, jenis kegiatan, fasilitas, dan penggunaannya dalam melakukan interaksi. Kombinasi yang berbeda menimbulkan hasil belajar yang berbeda. Joyce dan Well (dalam Rusman , 2010) menjelaskan bahwa model 
pembelajaran merupakan model yang digunakan untuk menciptakan kondisi belajar atau deskripsi dari lingkungan belajar yang menggambarkan perencanaan kurikulum, kursus-kursus, rancangan unit pembelajaran, perlengkapan belajar, bukubuku pelajaran, program multimedia dan bantuan belajar melalaui program komputer.

Merujuk pada pendapat-pendapat di atas, model pembelajaran dapat diartikan sebagai suatu rencana yang memperlihatkan pola pembelajaran tertentu, dalam pola tersebut dapat terlihat kegiatan guru dan peserta didik di dalam mewujudkan kondisi belajar atau sistem lingkungan yang menyebabkan terjadinya belajar pada peserta didik. Di dalam pola pembelajaran yang dimaksud terdapat karakteristik berupa rentetan atau tahapan perbuatan/kegiatan guru peserta didik yang dikenal dengan istilah sintaks.

Jadi dapat disimpulkan bahwa model pembelajaran adalah seperangkat prosedur yang sistematis sebagai perancang bagi para pengajar untuk mencapai tujuan belajar.

\section{Model Pembelajaran Kooperatif}

Model pembelajaran kooperatif merupakan sebuah prosedur yang sistematis dalam menggorganisasikan pengalaman belajar untuk mencapai tujuan pembelajaran. Model pembelajaran dapat dipandang sebagai titik awal dalam melaksanakan pembelajaran dan guru selanjutnya dapat menciptakan model pembelajaran sendiri, karena model pembelajaran hendaknya tidak dipandang sebagai resep, melainkan sebagai perangsang dalam melakukan pembelajaran (as stimulators to activity). Pembelajaran hendaknya dipandang sebagai upaya dalam menciptakan kondisi belajar yang mencakup materi, keterampilan, hubungan social, jenis kegiatan, fasilitas, dan penggunaannya dalam melakukan interaksi (Raka Rasana, 2009:2).

Menurut Arends (dalam Suprijono, 2009:46) model pembelajaran mengacu pada pendekatan yang akan digunakan, termasuk didalamnya tujuan-tujuan pembelajaran, tahap-tahap dalam kegiatan pembelajaran, lingkungan pembelajaran, dan pengelolaan kelas. Model pembelajaran dapat didefinisikan sebagai kerangka konseptual yang melukiskan prosedur sistematis dalam mengorganisasikan pengalaman belajar untuk mencapai tujuan belajar.

Dari pendapat-pendapat di atas, model pembelajaran dapat diartikan sebagai suatu rencana yang memperlihatkan pola pembelajaran tertentu, dalam pola tersebut dapat terlihat kegiatan guru dan peserta didik di dalam mewujudkan kondisi belajar atau sistem lingkungan yang menyebabkan terjadinya belajar pada peserta didik. Di dalam pola pembelajaran yang dimaksud terdapat karakteristik berupa rentetan atau tahapan perbuatan/kegiatan guru peserta didik yang dikenal dengan istilah sintaks. Jadi dapat disimpulkan bahwa model pembelajaran adalah seperangkat prosedur yang sistematis sebagai perancang bagi para pengajar untuk mencapai tujuan belajar.

\section{Model Pembelajaran Example Non Example}

Berbagai model pembelajaran secara umum telah banyak dibahas dan diterapkan dalam dunia pendidikan. Berbagai model pembelajaran banyak dikembangkan berdasarkan paham konstruktivisme. Salah satunya adalah model Example Non Example.

Model Examples Non Examples merupakan salah satu pendekatan Group investigation dalam pembelajaran kooperatif yang dirancang untuk mempengaruhi pola interaksi siswa dan meningkatkan perolehan hasil akademik. Tipe pembelajaran ini dimaksudkan sebagai alternatif terhadap model pembelajaran kelas tradisional dan menghendaki siswa saling membantu dalam kelompok kecil dan lebih dicirikan oleh penghargaan kooperatif dari pada individu.(Muslimin Ibrahin, 2000 : 3)

Pembelajaran Examples Non Examples adalah salah satu contoh model Jurnal Pendidikan Teknik Mesin Undiksha | 40 
pembelajaran yang menggunakan media. Media dalam pembelajaran merupakan sumber yang digunakan dalam proses belajar mengajar. Manfaat media ini adalah untuk guru membantu dalam proses mengajar, mendekati situasi dengan keadaan yang sesungguhnya. Dengan media diharapkan proses belajar dan mengajar lebih komunikatif dan menarik. Model pembelajaran Example Non Example merupakan "salah satu model pembelajaran kooperatif yang menggunakan media gambar dalam penyampaian materi pembelajaran yang bertujuan mendorong siswa untuk belajar berfikir kritis dengan jalan memecahkan permasalahan-permasalahan yang terkandung dalam contoh-contoh gambar yang disajikan."

Pembelajaran kooperatif model Examples Non Examples memberi ruang dan kesempatan yang luas kepada setiap anggota kelompok untuk bertatap muka saling memberikan informasi dan saling membelajarkan. Interaksi tatap muka akan memberikan pengalaman yang berharga kepada setiap anggota kelompok untuk bekerja sama, menghargai setiap perbedaan, memanfaatkan kelebihan masing-masing anggota dan mengisi kekurangan masing-masing.

\section{Hasil Belajar}

Ketika seseorang mengalami permasalahan dalam hidupnnya, maka yang dilakukan adalah mencari solusi dari permasalahan tersebut. Solusi yang ditemukan, selanjutnya digunakan untuk merubah sikap agar tidak ditemukan lagi permasalahan serupa. Perubahan tingkah laku tersebut dapat kita sebut sebagai hasil belajar.

Makna hasil belajar yaitu perubahan-perubahan yang terjadi pada diri siswa, baik yang menyangkut aspek kognitif, afektif, dan psikomotor sebagai hasil dari kegiatan belajar (Susanto, 2013). Hasil belajar menurut Bloom (dalam, Rasyid 2007:13) mencakup peringkat dan tipe prestasi belajar, kecepatan belajar, dan hasil efektif. Andersen, (dalam Rasyid,
2007) sependapat dengan Bloom bahwa karakteristik manusia meliputi cara yang tipikal dari berpikir, berbuat, dan perasaan. Tipikal berpikir berkaitan dengan ranah kognitif, tipikal berbuat berkaitan dengan ranah psikomotor, dan tipikal perasaan berkaitan dengan ranah kognitif. Ketiga ranah tersebut merupakan karakteristik manusia dan dalam bidang pendidikan ketiga ranah tersebut merupakan hasil belajar.

Berdasarkan pemaparan tersebut, yang dimaksud dengan hasil belajar adalah hasil dari proses pembelajaran yang telah dilaksanakan dalam mata pelajaran Chasis.

Susanto (2013:14) mengidentifikasi faktor-faktor yang memengaruhi hasil belajar ke dalam sepuluh macam, yaitu : kecerdasan, kesiapan anak, bakat anak, kemauan belajar, minat anak, model penyajian materi, pribadi dan sikap guru, suasana belajar, kompetensi guru, dan kondisi masyarakat. Susanto (2013:14) mengidentifikasi faktor-faktor yang memengaruhi hasil belajar ke dalam sepuluh macam, yaitu : kecerdasan, kesiapan anak, bakat anak, kemauan belajar, minat anak, model penyajian materi, pribadi dan sikap guru, suasana belajar, kompetensi guru, dan kondisi masyarakat.

\section{Metode Penelitian}

Penelitian ini merupakan penelitian Pra-eksperimen dengan desain "One-Shot Case Study" yang penelitiannya hanya terdapat satu kelas yang diberikan treatment/perlakuan yaitu dengan model pembelajaran kooperatif tipe Example Non Example. Penelitian ini dilaksanakan pada tanggal 17 juli sampai 12 agustus $2017 \mathrm{di}$ SMK Negeri 3 Singaraja.

Jurnal Pendidikan Teknik Mesin Undiksha | 41 
JJTM, Vol. 5 No. 3, November 2017

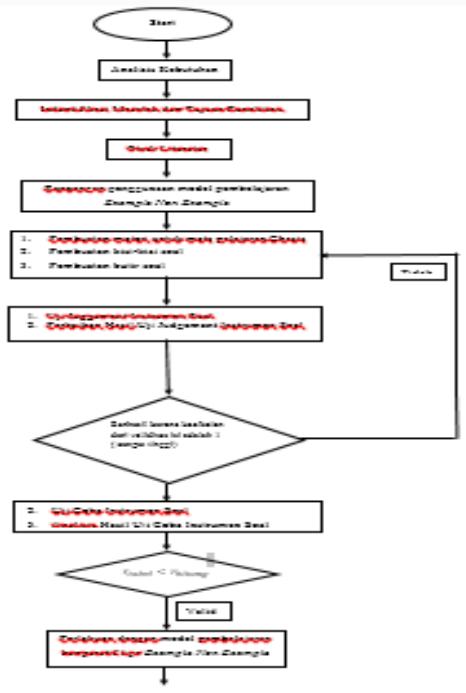

$\overline{\underline{20}}$

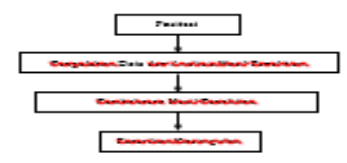

Gambar 1 Flow Chart Penelitian

\section{Hasil dan Pembahasan}

Berikut adalah nilai akhir dari kelas eksperimen setelah dilakukan perlakuan berupa implementasi model pembelajaran kooperatif tipe Example Non Example pada materi Transmisi Manual.

Tabel 1

Nilai Akhir Kelas Eksperimen

\begin{tabular}{|c|c|c|c|c|c|}
\hline No & Nis & Inisial Siswa & Nilai (X) & D & D $^{2}$ \\
\hline 1 & 16352 & AL & 96 & 26 & 676 \\
\hline 2 & 16322 & DJ & 60 & -10 & 100 \\
\hline 3 & 16353 & ER & 68 & -2 & 4 \\
\hline 4 & 16355 & TD & 92 & 22 & 484 \\
\hline 5 & 16356 & DC & 76 & 6 & 36 \\
\hline 6 & 16387 & PG & 88 & 18 & 324 \\
\hline 7 & 16357 & BD & 72 & 2 & 4 \\
\hline 8 & 16358 & AM & 96 & 26 & 676 \\
\hline 9 & 16359 & DA & 68 & -2 & 4 \\
\hline 10 & 16360 & AS & 88 & 18 & 324 \\
\hline 11 & 16361 & KS & 92 & 22 & 484 \\
\hline 12 & 16362 & AW & 96 & 26 & 676 \\
\hline 13 & 16363 & KA & 84 & 14 & 196 \\
\hline 14 & 16364 & AW & 88 & 18 & 324 \\
\hline 15 & 16365 & AP & 76 & 6 & 36 \\
\hline 16 & 16366 & ASM & 88 & 18 & 324 \\
\hline 17 & 16367 & DP & 80 & 10 & 100 \\
\hline 18 & 16368 & PA & 92 & 22 & 484 \\
\hline 19 & 16369 & MS & 96 & 26 & 676 \\
\hline 20 & 16370 & NS & 84 & 14 & 196 \\
\hline 21 & 16371 & RR & 72 & 2 & 4 \\
\hline 22 & 16372 & SA & 68 & -2 & 4 \\
\hline 23 & 16373 & ST & 80 & 10 & 100 \\
\hline 24 & 16340 & GN & 96 & 26 & 676 \\
\hline 25 & 16374 & KKA & 72 & 2 & 4 \\
\hline 26 & 16375 & S & 88 & 18 & 324 \\
\hline 27 & 16376 & LN & 84 & 14 & 196 \\
\hline 28 & 16377 & MI & 76 & 6 & 36 \\
\hline 29 & 16378 & PV & 92 & 22 & 484 \\
\hline 30 & 16379 & AD & 68 & -2 & 4 \\
\hline 31 & 16380 & ES & 96 & 26 & 676 \\
\hline 32 & 16382 & RR & 56 & -14 & 196 \\
\hline 33 & 16383 & RP & 2792 & - & 9128 \\
\hline 34 & 16384 & NW & 82,11 & - & - \\
\hline & & Iumlab $(\Sigma)$ & & & \\
\hline & & & 10 & 100 \\
\hline & & & & & \\
\hline & & & 96 & & \\
\hline
\end{tabular}

Berdasarkan penelitian dikelas XI TKR II setelah dilakukan treatment/perlakuan berupa implementasi model pembelajaran kooperatif tipe Example Non Example dalam proses pembelajaran, dicapai nilai tertinggi 96 dan nilai terendah 56. Kemudian dilakukan pengujian normalitas. Uji normalitas data dimaksudkan untuk memperlihatkan bahwa data sampel berasal dari populasi yang berdistribusi normal. Uji normalitas data dalam penelitian ini menggunakan statistic Kolmogorov-Smirnov test. berbantuan SPSS-20 for windows. Kriteria pengujian yang digunakan adalah data memiliki sebaran normal jika angka signifikansi yang dihasilkan lebih dari 0,05 (taraf signifikasi nyata) dan dalam hal lain data tidak berdistribusi normal. Berikut adalah hasil pengujian normalitas.

Tabel 2 Uji normalitas

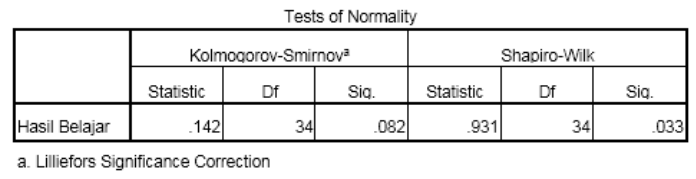

Jurnal Pendidikan Teknik Mesin Undiksha | 42 
JJTM, Vol. 5 No. 3, November 2017

Berdasarkan uji normalitas dengan menggunakan statistic Kolmogorov-Smirnov test berbantuan SPSS-20 for windows didapat nilai signifikasinya adalah 0,069. Karena nilai signifikansi 0,082 > 0,05 maka dapat disimpulkan data diatas berdistribusi normal.

\section{Pengujian Hipotesis}

Pada kelas eksperimen yang diberikan perlakuan/treatmen khusus yaitu dengan menggunakan model pembelajaran kooperatif tipe Example Non Example pada mata pelajaran Chasis materi pokok Transmisi Manual. Untuk mengetahui pengaruh model pembelajaran kooperatif tipe Example Non Example terhadap hasil belajar Chasis materi pokok Transmisi Manual peserta didik kelas eksperimen, dapat ditunjukkan dengan uji-t sebagai berikut.

Pengujian hipotesis menggunakan uji-t dengan nilai yang dihipotesiskan yaitu 70 (KKM). Karena nilai post-test kelas eksperimen berdistribusi normal, maka digunakan rumus:

$$
t=\frac{\bar{X}-\grave{i}}{\sqrt{\frac{\sum D^{2}}{N\left(N^{2}-1\right)}}}
$$

(Dantes, 2014:58)

Dimana:

$D=X-\grave{i ̀ ~}$

Keterangan :

\section{Menghitung rata - rata}

$$
\begin{aligned}
& \bar{X}: \text { Rata - rata } \\
& \text { ì: } K K M(70,00)
\end{aligned}
$$

$$
\text { Mean }=\frac{\sum \mathrm{x}}{\mathrm{n}}=\frac{2792}{34}=\mathbf{8 2 , 1 1}
$$

Dari perhitungan diatas didapat nilai rata - rata hasil belajar pada mata pelajaran Chasis materi pokok Transmisi Manual adalah 82,11. Dapat disimpulkan bahwa implementasi model pembelajaran kooperatif tipe Example Non Example berpengaruh terhadap hasil belajar siswa kelas XI TKR II di SMK Negeri 3 Singaraja pada mata pelajaran Chasis materi pokok Transmisi Manual.

Kriteria Ketuntasan Minimal (KKM) mata pelajaran Chasis materi pokok Transmisi Manual adalah 70,00 sehingga dalam analisis data yang akan dilakukan diperoleh ì $=70,00$.

\section{Menghitung t-hitung}

$$
\begin{aligned}
& t=\frac{\bar{X}-\mu}{\sqrt{\frac{\sum D^{2}}{N\left(N^{2}-1\right)}}} \\
& t=\frac{82,11-70}{\sqrt{\frac{9128}{34\left(34^{2}-1\right)}}} \\
& t=\frac{12,11}{\sqrt{\frac{9128}{39270}}} \\
& t=\frac{12,11}{\sqrt{0,1022}} \\
& t=\frac{12,11}{0,319} \\
& t=37,96
\end{aligned}
$$

(Dantes, 2014:58)

Berdasarkan analisis diatas, didapat $\mathrm{t}_{\text {hitung }}=37,96$ dan nilai $\mathrm{t}$ tabel untuk taraf signifikan $5 \%$ dan derajat kebebasannya $(\mathrm{dk})=29-1=28$ didapat nilai $\mathrm{t}$ tabel 2,0345 . Karena t hitung 37,96 > t tabel 2,0345 sehingga $\mathrm{H}_{0}$ ditolak dan $H_{1}$ : $\grave{\mathrm{i}}_{0}>70(\mathrm{KKM})$ diterima. Maka dapat disimpulkan bahwa, terdapat pengaruh yang siginifikan implementasi model pembelajaran Example Non Example terhadap hasil belajar Chasis kelas XI TKR II di SMK Negeri 3 Singaraja.

\section{Kesimpulan}

Dari pembahasan diatas dapat disimpulkan bahwa di dapatkan nilai rata rata hasil belajar Chasis dengan model pembelajaran Example Non Example lebih tinggi dari pada nilai 70,00 (KKM). Berdasarkan perhitungan yang telah diperoleh dalam penelitian menunjukan bahwa rata - rata hasil belajar kelas eksperimen diperoleh $\overline{\mathrm{x}}$ 82,11. Setelah perhitungan akhir dengan uji-t satu pihak diperoleh $t_{\text {hitung }}$ 37,96. Kemudian dikonsultasikan ke dalam tabel distribusi uji-

Jurnal Pendidikan Teknik Mesin Undiksha | 43 
JJTM, Vol. 5 No. 3, November 2017

t satu pihak dengan $\mathrm{dk}=\mathrm{n}-1=29-1=28$ dan taraf signifikan 5\% didapat $t_{\text {tabel }} 2,0345$. Ini berarti $\mathrm{t}_{\text {tabel }}<\mathrm{t}_{\text {hitung. Sehingga } \mathrm{H}_{0} \text { ditolak }}$ dah $\mathrm{H}_{1}$ diterima dan dapat disimpulkan bahwa terdapat pengaruh yang signifikan dari implementasi model pembelajaran kooperatif tipe Example Non Example terhadap hasil belajar Chasis kelas XI TKR II di SMK Negeri 3 Singaraja.

\section{Saran}

Dengan mengunakan model pembelajaran Example Non Example dapat meningkatkan hasil belajar siswa kelas XI TKR di SMK Negeri 3 Singaraja. Model pembelajaran ini sudah terbukti bermanfaat bagi para guru yang dapat digunakan sebagai salah satu alternatif memilih model pembelajaran dalam upaya meningkatkan hasil belajar Chasis serta mengurangi dominasi guru dalam pembelajaran.

\section{Daftar Rujukan}

Adnyani, I.A.K. 2016. "Pengaruh Model Pembelajaran Kooperatif Tipe Examples Non Examples Untuk Meningkatkan Pemahaman Konsep IPA Siswa". Singaraja. e-Journal Mimbar PGSD Universitas Pendidikan Ganesha Vol: 4 No: 1 Tahun 2014.

Arikunto, Suharsimi. 2012. Dasar-Dasar Evaluasi Pendidikan (Edisi Revisi). Jakarta: PT Bumi Aksara.

Candiasa, I Made. 2011. Pengujian Instrumen Penelitian Disertasi Aplikasi ITEMAN dan BIGSTEPS. Singaraja: Undiksha Press.

Dantes. 2014. Analisis dan Desain Eksperimen, Program Pasca Sarjan : Undiksha

Ibnu Hadjar. 1996. Dasar-dasar Metodologi Penelitian Kwantitatif dalam Pendidikan. Jakarta: RajaGrafindo Persada.

Isjoni. 2009. Pembelajaran Kooperatif. Yogyakarta: Pustaka Pelajar.
Isjoni. 2009. Cooperative Learning. Bandung: Alfabeta.

Koyan. I Wayan. 2012. Statistik Pendidikan Teknik Analisis Data Kuantitatif. Singaraja: Universitas Pendidikan Ganesha Press.

Mardapi, Djemari. 2008. Teknik Penyusunan Instrumen Tes dan Non tes. Yogyakarta : Mitra Cendikia.

Muslimin Ibrahim. 2000. Pembelajaran Kooperatif Tipe Example Non Example. Surabaya: University Press.

Putera, Cahyana. 2016. "Studi Komperatif Pengunaan Model Pembelajaran Picture and Picture dan Example Non Example Terhadap Minat dan Hasil Belajar Siswa". Karmawati. eJournal Pendidikan Teknik Informatika Vol: 5 No: 2 Tahun 2016.

Rahmayudi, Rahmad. 2007. Kapita Seleksa Pembelajaran. Banjarmasin : UNLAM.

Rasyid, Harun. 2007. Penilaian Hasil Belajar.Bandung: CV Wacana Prima.

Rusman. 2012. Model-Model Pembelajaran Mengembangkan Profesionalisme Guru. Jakarta: PT Raja Grafindo Persada.

Suprijono, Agus. 2009. Cooperative Learning Teori dan Aplikasi PAIKEM. Yogyakarta: Pustaka Belajar.

Susanto, Ahmad. 2013. Teori Belajar dan Pembelajaran. Jakarta: Kencana Prenada Media Group.

Trianto. 2009. Mendesain Model pembelajaran Inovatif-Progresif: Konsep, Landasan, dan Implementassinya pada Kurikulum Tingkat Satuan Pendidikan (KTSP). Jakarta: Kencana.

Wardika, I.K. 2014. "Pengaruh Model Examples Non Examples Terhadap Hasil Belajar IPA Siswa Kls V SD Di Gugus III Kecamatan Tampaksiring". Singaraja. e-Journal Mimbar PGSD Universitas Pendidikan Ganesha Vol: 2 No: 1 Tahun 2014. 